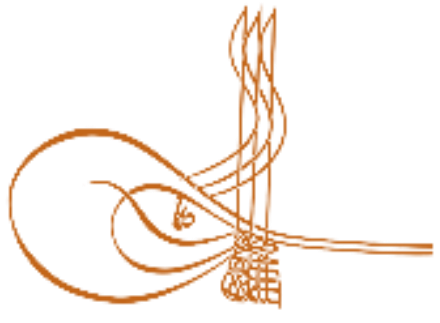

www.turkishstudies.net/social
Turkish Studies - Social Sciences

eISSN: $2667-5617$

Research Article / Araşttrma Makalesi

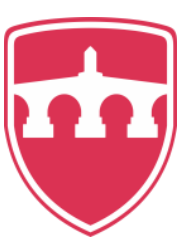

INTERNATIONAL

BALKAN

UNIVERSITY

Sponsored by IBU

\title{
Türk Dünyası'nda Sosyal Sermaye, Kültürel Sermaye, Sosyal Yenilikçilik Üzerine Bir Araştırma: Türkiye-Azerbaycan Üniversite Öğrencileri Örneği
}

\author{
A Study on Social Capital, Cultural Capital and Social Innovativeness in Turkish World: A Sample \\ of Turkey-Azerbaijan University Students
}

\author{
Burcu Üzüm* - Leyla Şenol ${ }^{* *}$ - Reyhan Dadashova ${ }^{* * *}$
}

\begin{abstract}
Culture is all the values that create a society. Therefore; data on the development of a society can be obtained by examining the culture of that society. In this study; It is aimed to determine the levels of social capital, cultural capital and social innovation that reflect the Turkish culture and which can reveal the richness of the Turkish world. University students, which are elements of Turkish culture, have been the subject of examination. In this respect, Turkey and Turkish nationals studying, Azeri students studying in Azerbaijan is the main mass of the research. The sample of the study consisted of 196 students. The study was conducted between April and June 2019. The research method is quantitative; data collection tool is survey. Social innovation, social capital strategic trust, cultural capital scales were used in the survey. Five demographic variables such as nationality, age, gender, department, income are also included in the questionnaire form. The research was conducted in two public universities. Importance of research; Studying in Azerbaijan and Azeri students studying at Turkish nationals in Turkey in social capital, cultural capital, it is based on the shortage of studies investigating along with the concept of social innovation. As a result of the research, it is seen that there is a difference between the strategic trust of the cultural capital and the cultural participation between the Azerbaijani students and the Turkish students. It was determined that social capital and cultural capital positively increased social innovation. In addition to this information, it was determined that the related concepts were affected by some demographic variables.
\end{abstract}

\footnotetext{
* Dr., Kocaeli Üniversitesi, Kocaeli MYO, Uzaktan Eğitim Birimi PhD, Kocaeli University, Kocaeli Vocational High School, Distance Education ORCID 0000-0001-8675-8952

burcugokay@gmail.com

** Dr., Kocaeli Üniversitesi, Ali Rıza Veziroğlu MYO, Emlak Yönetimi

PhD, Kocaeli University, Ali Rlza Veziroğlu Vocational High School, Property Management

ORCID 0000-0002-5780-9690

senolleyla4@gmail.com

**** Dr., Azerbaycan Devlet Pedagoji Üniversitesi, Filoloji Fakültesi, Edebiyat Bölümü

PhD, Azerbaijan State Pedagogical University, Faculty of Philology, Department of Literature

ORCID 0000-0002-3407-2817

reyhandadash72@gmail.com

Cite as/ Atıf: Üzüm, B., Şenol, L., Dadashova, R. (2020). Türk dünyası'nda sosyal sermaye, kültürel sermaye, sosyal yenilikçilik üzerine bir araştırma: Türkiye-Azerbaycan üniversite öğrencileri örneği, Turkish Studies - Social, 15(3), 1625-1642. https://dx.doi.org/10.29228/TurkishStudies.40298

Received/Geliş: 25 December/Aralık 2019

Checked by plagiarism software

Accepted/Kabul: 25 April/Nisan 2020

Published/Yayın: 30 April/Nisan 2020

Copyright $(C)$ INTAC LTD, Turkey

CC BY-NC 4.0
} 
Structured Abstract: Culture is a set of values that are learned throughout life and are inherently connected. The research of the impact of culture on individuals and society at social and organizational level has been of interest. Culture has an important role in understanding and interpreting the effects and results it has on the functioning of the organization and in solving the problems that may occur later. In addition to this role, it also provides information on social development. Culture is the collection of values forming a society. Therefore, the data about a society's development can only be gathered through examining that society's culture. In this study, it has been aimed at determining the levels of social capital, cultural capital and social innovativeness which demonstrate the richness of Turkish world and reflect Turkish culture. In this respect, Azerbaijani students studying in Azerbaijan with Turkish students studying in Turkey have been the subject of research.

In this study, firstly, the concepts of social capital, cultural capital and social innovation which affect social development are explained. The social capital, cultural capital and social innovation levels of the university students studying in Turkey and Azerbaijan which have bonds with Turkish culture have been determined and a comparison has been made. What makes this study important is the fact that there has not been enough researches studying these two countries in terms of related concepts and that it will strengthen the ties between the two countries. The population of the study consists of students studying aviation management at the Faculty of Aviation and Space Sciences from Kocaeli University as a representative of Turkey and students studying philology, history, pedagogy, literature at Azerbaijan State Pedagogical University as a representative of Azerbaijan. The students studying in the mentioned departments were easily selected according to the sampling method and formed the research sample. The sample of the study consisted of 196 students. The study was conducted between April and June 2019. The reason why only the strategic confidence dimension of the social capital scale was included in the survey questions is that total number of questions of the scale is too many; hence, it may reduce the likelihood of answering all the questions due to the fact that it might cause tedium. In addition to the three scales, there are five demographic variables in terms of nationality, age, gender, department and income.

In the study; explanatory factor analysis, correlation, regression analysis, t-test, one-way analysis of variance were performed. Data analysis was performed using SPSS21 version. The analyzes were performed with 0.05 significance level. The hypotheses prepared in accordance with the aim of the research are given below:

$\mathrm{H}_{1}$ : There is a significant difference between the level of strategic trust in the social capital of Azerbaijani and Turkish students.

$\mathrm{H}_{2}$ : There is a significant difference between Azeri and Turkish students' cultural capital levels.

$\mathrm{H}_{3}$ : There is a significant difference between the levels of social innovation among Azerbaijani and Turkish students.

$\mathrm{H}_{4}$ : There is a difference between the demographic variables of students and the dimension of strategic trust in social capital. dimensions.

$\mathrm{H}_{5}$ : There is a difference between students' demographic variables, cultural capital and sub-

$\mathrm{H}_{6}$ : There is a difference between students' demographic variables and social innovation.

At the end of the study, it has been realized that there is a difference between Azerbaijani students and Turkish students in terms of social capital, strategic thrust, cultural capital and cultural dissociation. It has been identified that social capital and cultural capital affect cultural capital in a positive way. Moreover, it has also been confirmed that related concepts have also been influenced by some demographic variables.

Considering that culture is a wealth of that nation, the concepts of social capital, cultural capital and social innovativeness stand out as elements of culture. The development of a country depends on its effective use of its social capital and cultural capital. In this study, the students selected as samples continue their lives in the lands of their own countries. In other words, Turkish or Azeri students participated in this study by taking part in the cultural climate of their country. The aim of this study is to examine whether there is a difference between the levels of social capital, cultural capital and social innovation among the youth of two different countries belonging to the same culture. It has been understood that the social capital and strategic thrust levels of Turkish students living in Turkey are higher than the Azerbaijani students living in Azerbaijan. The $\mathrm{H}_{1}$

Turkish Studies - Social, 15(3) 
hypothesis was accepted. As a reason for this situation; Considering that the origins of both countries are Turkish, it is thought that the students who share the same culture may be affected by the geographical, economic and strategic location of the countries. When the results related to cultural capital were examined, the level of cultural participation of Azerbaijani students was found to be higher than that of Turkish nationals. The hypothesis $\mathrm{H}_{2}$ was partially accepted. The fact that cultural participation, which is a dimension of cultural capital, is in favor of Azerbaijani students is thought to be due to the greater value they give to their cultural heritage. $\mathrm{H}_{4}$ was accepted as there was a significant difference between age, department, income, gender, nationality and strategic trust in social capital. Since there is a significant difference between department, gender, nationality and cultural capital or dimensions, $\mathrm{H}_{5}$ was partially accepted. Hometown as cultural feature, avoidance of uncertainty, collectivist approaches are the result of trust based on relationships. Considering gender-based findings; supporting women is seen as an investment in the economy and the future of the country. Cooperation between the two countries and the use of common resources should be ensured and strategic trust should be provided. Any initiative that promotes cultural values such as policies and the education system should be supported.

Keywords: Azerbaijan, Turkey, Turkish culture, social capital, cultural capital, social innovativeness.

Öz: Kültür bir toplumu var eden değerlerin tümüdür. Bu nedenle; bir toplumun gelişimi hakkındaki veriler o toplumun kültürünün incelenmesiyle elde edilebilir. Bu araştırmada; Türk dünyasının kendi zenginliğini ortaya koyabilecek ve Türk kültürünü yansıtan sosyal sermaye, kültürel sermaye, sosyal yenilikçilik düzeylerinin tespit edilmesi amaçlanmıştır. Türk kültürünün birer öğesi olan üniversite öğrencileri inceleme konusu olmuştur. Bu doğrultuda araştırmanın ana kütlesini Türkiye öğrenim gören Türk uyruklu ve Azerbaycan'da öğrenim gören Azeri uyruklu öğrenciler oluşturmaktadır. Araştırmanın örneklemi 196 öğrenciden oluşmaktadır. Araştırmanın uygulaması 2019 yılı nisan-haziran ayları arasında gerçekleştirilmiştir. Araştırma yöntemi nicel olup; veri toplama aracı ankettir. Ankette sosyal yenilikçilik, sosyal sermaye stratejik güven, kültürel sermaye ölçekleri kullanılmıştır. Anket formunda uyruk, yaş, cinsiyet, bölüm, gelir olarak beş adet demografik değişkenlere ait sorular da mevcuttur. Araştırma iki devlet üniversitesinde gerçekleştirilmiştir. Araştırmanın önemi; Azerbaycan'da öğrenim gören Azeri uyruklu ve Türkiye'de öğrenim gören Türk uyruklu öğrencilerin sosyal sermaye, kültürel sermaye, sosyal yenilikçilik kavramlarını birlikte inceleyen araştırmaların az oluşuna dayanmaktadır. Araştırma sonucunda Azeri uyruklu öğrencilerle Türk uyruklu öğrenciler arasında sosyal sermaye stratejik güven, kültürel sermaye kültürel katılım arasında farklılık olduğu görülmüştür. Sosyal sermayenin ve kültürel sermayenin sosyal yenilikçiliği olumlu yönde artırdığı belirlenmiştir. Bu bilgilerin yanı sıra ilgili kavramların bazı demografik değişkenlerden etkilendiği de tespit edilmiştir.

Anahtar Kelimeler: Azerbaycan, Türkiye, Türk kültürü, sosyal sermaye, kültürel sermaye, sosyal yenilikçilik

\section{Giriş}

Kültür; bir toplumu oluşturan bireylerin birlikte yaşamaya başlamasıyla birlikte bu ortak yaşam sürecinde gelişen normlar, değerler ve inançların toplamından oluşmaktadır. Toplumu yalnızca kalabalık yığınlar olmaktan çıkaran, onun var olmasına sebep olan, bireyler arasında manevi olarak bağ kurulmasını sağlayan en önemli birliktelik unsuru; toplumun kültürel birikimi ve değerleridir. Bu açıdan bakıldığında; tarih, coğrafya, dil, din ve halk inançları kültürü, ana unsurlar olarak ortaya çıkarmaktadır. Türk kültürünün ve Türk dilinin, Türk tarihinin, örf-adetlerinin, geleneklerinin, inançlarının ve değerlerinin incelendiği bilimsel çalışmaların önem kazandığ görülmektedir. Çünkü; kendi tarihi, dili, değerleri ve kültürü hakkında bilgi sahibi olmayan ve sahiplenici olmayan ülkelerin ve milletlerin öz benliklerini kaybettiklerini ya da kaybedebileceklerini ifade etmek yerinde olacaktır (Çeltikçi 2016).

Türk toplumun gelenek ve göreneklerinin sürdürülmesi ve öğrenilmesi her zaman gündemde olmuştur. Çünkü gelenek ve görenekler, tarihin bütün aşamalarında toplumsal ve kültürel gelişmelerin en önemli göstergelerinden biridir. Gelenek ve görenekler sosyo-politik açıdan bir şekilde toplumda meydana gelen ilerleme ve gelişmelere aktarılmaktadır (Keskin ve Dadaş 2018). $\mathrm{Bu}$ nedenle toplumsal gelişmeyi sağlayan kaynağın kültür olduğu unutulmamalıdır. Bireylerin 
yaşamı boyunca öğrendiği ve doğuştan bağlı olmadıkları değerler bütünü olarak kültürün; bireyler ve toplum üzerindeki etkisinin toplumsal ve örgütsel bağlamda araştırılması ilgi çekmiştir. Araştırılan kavramlardan bazılarının sosyal sermaye, kültürel sermaye, sosyal yenilikçilik olduğunu belirtmek mümkündür.

Kültürün toplumsal gelişimle ilişkisi sosyal sermaye ile tanımlanabilir. Bir toplumda mevcut maddi kaynakların üretime katılması ekonomik sermaye olarak tanımlanabilirken sosyal sermaye hem ekonomik hem de kültürel olarak nitelendirilen kaynakların tamamıdır (A ğcasulu 2017: 115). Kültürel sermaye ise; tek başına ekonomik değeri olmayan kültürel açıdan çeşitli becerileri kapsamına alan üretime katılabilen kaynakların toplamıdır (Yanıklar 2010: 124; Yaşar 2016: 205).

Hem toplumsal hem örgütsel anlamda sosyal sermaye bireyler arasındaki bağlar, ulaşılması arzulanan amaçlar, uyulması gereken normlar ile güveni ifade eder (Baharloo ve Naghavi 2012). Güven ise toplum üyelerini birbirine bağlayan yegane unsurdur. Güven dengesi bozulduğunda o toplumda kopmalar, parçalanmalar söz konusu olur. Kültürün bağlayıcı, birleştirici özelliği de kendiliğinden kaybolur. Organizasyonlar üzerinde yarattığı etkilerini ve sonuçlarını anlamada, yorumlamada ve daha sonra oluşabilecek sorunların çözümünde kültürün önemli bir rolü bulunurken kültür toplumsal ilerleme konusunda da bilgi vermektedir.

Toplumlar zaman içinde gelişir ve değişir. Bu değişimsel hareketlilik yeni ihtiyaçların doğmasına yol açar. Girişimciler toplumun ihtiyaçlarını karşılayacak sermayeyi tek elde toplayabilme becerisine sahiptirler (Özdemir ve Ar 2015: 19). Özetle, sosyal yenilikçilik kültürel sermayeyi sosyal sermayeye dönüştürebilme yeteneği olarak tanımlanabilmektedir. Bir toplumun ekonomik yönden gelişimi, onun kültürel zenginliği ve bu zenginliği üretime ne kadar aktarabildiği, ortaya çıkan ihiyaçlara ne oranda çözüm bulabildiği ile ilgilidir.

\section{Kültür; Sosyal Sermaye, Kültürel Sermaye, Sosyal Yenilikçilik}

Kültür; toplumu oluşturan bireyler tarafindan meydana getirilen ve ilgili toplumun diğer üyelerine aktarılan inanç, düşünce ve kuralların tamamıdır (Zengin ve Tokucu 2019: 1141). Daha geniş bir tanımla kültür; "Tarihsel, toplumsal süreç içinde oluşan bütün maddi ve manevi değerlerin tamamı ve sonraki nesillere aktarmada kullanılan, insanın doğal ve toplumsal çevresine egemenliğinin ölçüsünü gösteren araçların bütünü”dür (TDK 2019). Kültür, toplumsal yaşamla birlikte oluşan bir olgudur. Bu açıdan birliktelik, bütünleşme kavramlarına vurgu yapar. Kültür; "Doğal ve toplumsal çevrenin türlü nesneleri ve bu çevre içindeki türlü insanlar aras1 etkileşimleri yönlendiren düşünceler, duygular, tutum ve davranışlar toplamıdır" (Ozankaya 1992). Kültür kavram olarak sosyoloji biliminin inceleme konusu gibi görünse de tarih, edebiyat, yönetim bilimleri gibi çok çeşitli bilimler tarafından ele alınan ve araştırılan bir kavramdır (Mutlu 2016; Alver 2010; Giddens 2014; Horata 2017; Maden 1993; Sargut 2001, Güçlü, 2003). Kültür ve toplumla yakından ilişkili olan sosyal sermaye kavramında ilişkiler önemlidir (Field 2005). Kısaca bir ülkenin kültürel birikimleri sosyal sermayeyi oluşturmaktadır.

Bourdieu (1986) sosyal sermayeyi; karş1lıklı olarak tanınma, bir gruba üye olma veya kurumsallaşmış kalıcı bir ilişki ağına sahip gerçek veya potansiyel kaynakların toplamı olarak tanımlamıştır. Bourdieu (1983) kaynak niteliği taşıyan sosyal sermayeyi ekonomik yönden incelemiştir (Herreros 2004: 65'den ). Ancak Putnam sosyal sermayeye daha geniş bir perspektiften bakmış; ilgili toplum adına sosyal sermayeyi kaynak olarak ifade etmiştir (Field 2005). Coleman (1988) ise sosyal sermayeyi; "sosyal ilişkiler ve ilişkiler ağına bağlı bir yardım kaynağı" olarak tanımlamaktadır. Burt (1992) sosyal sermayeyi bireysel düzeyde başkalarıyla sürdürülen ilişkilerdeki gömülü kaynaklar olarak tanımlar. Organizasyon düzeyinde sosyal sermaye; bir kuruluşun üyeleri ile oluşturduğu ilişkiler açısından değeridir (Nahapiet ve Ghoshal 1998). Fukuyama sosyal sermayeyi; ulusal ekonomilerin "kültürel bir başarısı" olarak inovasyonun rekabet avantajına dönüştürülmesinin kilit anahtarı olarak açıklamaya çalışmıştır (Tittenbrun 2013). Bu 
tanımlamalardan hareketle ekonomik, sosyal, kültürel bakış açışıyla incelenen sosyal sermayenin tek bir disiplin konusu olarak görülememektedir (Beşer ve Hira 2017).

Toplumsal açıdan ilişkiler ister kurumsallaşmış olsun ister kurumsallaşmamış olsun, bağlılık oluşturabilme, değer yaratabilme, işbirliğine ve güvene dayalı birliğin sağlanması, o topluma ait benliğin kurulmasında önemli bir role sahiptir (Aydemir ve Tecim, 2012). Bu açıdan sosyal sermayenin kültürle sıkı ilişki içinde olduğunu belirtmek mümkündür. Sosyal sermaye toplumun etkinliğini artıran güven, norm, sosyal ağlar ve koordineli eylemlerin bütünüdür (Anderson ve Park 2007). Sosyal sermaye, tanımı gereği ekonomik gelişimin tetikleyicisi konumundadır. Hem kültürel sermaye hem de yenilikçilikle ilişki içerisindedir.

Tanımlardan anlaşılacağ birliktelik, ağlar kavramlarıyla iletişime vurgu yapmaktadır. Kültürel sermaye ise Bourdieu'ya göre; sosyal hareketliliği sağlayan ekonomik olmayan kaynakların tamamıdır (Raskoff 2014'den). Bazı ülkelerin nasıl bir özelliği vardır ki daha fazla yenilikçilik uygulamaları gerçekleştirebilirler? Sosyal yenilikçiliğin ilişkili olduğu kavramlar bu sorunun cevabını açıklar. Hofstede (1980) ülkeleri belirsizlikten kaçınma, bireyci-kollektivist, güç mesafesi, erillik-dişilik olarak kültürel boyutlar altında incelemiştir. Örneğin bireyci, güç mesafesinin ve belirsizlikten kaçınmanın düşük olduğu toplumlarda daha fazla yenilikçilik uygulamalarının gerçekleştirildiğini belirtmiş̧ir. Kısaca farklı kültürel değerlere sahip toplumlar farklı yenilikçilik davranışları göstermektedirler (Shane 1992'den; Shane 1995). Bu ifadelerden yola çıkarak yenilikçiliği gerçekleştirebilmenin kültürel bir özellik olduğu söylenebilir.

Peki sosyal sermaye toplumların gelişiminde neden önemlidir? Bu sorunun cevabı sosyal sermayenin aile, arkadaşlık, grup üyeliği gibi ilişkileri maddi veya manevi zenginlik olarak görmesinde yatmaktadır (Arıcıoğlu ve Ergin 2009). Ayrıca mevcut zenginlikler etkin kullanıldığında toplum adına yeni firsatlar ortaya çıkmaktadır (Narayan ve Pritchett 1999). Yıldız ve Topuz (2001)'da az gelişmiş ülkelerin gelişmişlik düzeylerini artırabilmeleri için sosyal sermayelerini artırmaları gerektiğini belirtmişlerdir (Yıldız ve Topuz 2011). Toplumdaki her bireyin mevcut yapıya dahil edilebilmesi ülkelerin gelişiminde ve varlığını devam ettirebilmelerinde önemli rol oynamaktadır (Eşkinat 2015). Türk toplumunun yakın ve samimi ilişkiler barındıran sosyal sermaye birikimlerine sahip olduğu belirtilebilir (Şan ve Akyiğit 2015).

\section{Yazın Taraması}

Araştırmanın konusunu oluşturan kavramlara yönelik literatür araştırması yapıldığında; Gökçe ve Eşki-Uğuz (2009)'un Selçuk Üniversitesi öğrencilerinin sosyal sermaye düzeylerini incelediği görülmektedir. Öğrencilerin özyeterlik, kontrol ve iletişim boyutlarında yüksek sosyal sermaye düzeyine sahip olduğunu belirlemişlerdir. Boz ve arkadaşları (2017) üniversite öğrencilerinin sosyal medya kullanımları ile sosyal sermaye düzeyleri arasındaki ilişkiyi araştırmışlar ancak düşük bir sosyal sermaye düzeyiyle karşılaşmışlardır. Seki ve Aydın (2019) yapmış oldukları çalışmada üniversite öğrencilerinin sosyal sermaye düzeylerinin güven boyutunda yetersiz olduğunu belirlemişlerdir. Toprak ve Bozgeyikli (2011) eğitim fakültesinde çeşitli bölümlerdeki öğrencilerin sosyal sermaye düzeylerinin incelemişlerdir. Öğrenim gördükleri programa göre öğretim elemanları ile ilişkiler, öğrencilerle ilişkiler, olumlu etki alt boyutu arasında anlamlı farklılık olduğunu bulmuşlardır.

Ardahan ve Ezici (2015) ilköğretim öğrencilerinin sosyal sermaye düzeylerini incelemişlerdir. Sosyal sermaye ile akademik başarı arasındaki anlamlı bir ilişki görülmüş, başarı düzeyinin yüksek olduğu okullarda gelir düzeyinin düşüklüğüne rağmen başarılı öğrencilere yatırım yapıldığı tespit edilmiştir. Dakhli ve Clercq (2004) elli dokuz farklı ülkeyi kapsam dahiline alarak insan sermayesi, sosyal sermaye ve yenilikçilik kavramlarını inceledikleri çalışmalarında insan sermayesi ile yenilikçilik arasında doğru yönlü ve pozitif bir ilişki bulmuşlardır. Güven bu ilişkiye kısmi destek sağlamaktadır. Arıcıŏlu ve Ergin (2009) ise sanayi işletmelerinde sosyal sermayeyi 
araştırmışlardır. Sosyal sermayenin alt boyutu olan stratejik güvenin ortak değerin, grup aidiyetinin, ilişkisel benliğin, cinsiyetin, yasa ve partilere güvenle anlamlı bir ilişki içinde olduğu görülmüştür (Uçar 2010). Nas (2017)'ın gerçekleştirmiş olduğu araştırma sonucunda ekonomik başarı açısından sosyal sermayenin güven boyutunun kültürel sermayeye göre ihracatı daha fazla etkilediği sonucuna ulaşılmıştır.

Şirin ve arkadaşlarının (2018) beden eğitimi ve spor yüksekokulunda öğrenim gören üniversite öğrencilerinin sosyal yenilikçilik düzeylerini inceledikleri araştırmalarında; cinsiyet, ebeveyn eğitim durumu gibi demografik değişkenlerle sosyal yenilikçilik arasında istatistiki olarak farklılık görülmüştür. Karahani ve Patır (2019) üniversite öğrencilerinin yenilikçilik eğilimlerini incelediği araştırmalarında öğrencilerin kendilerine olan güven ve bireysel yenilikçilik düzeylerinin yüksek ve öğrencilerin risk alabilme kapasitelerinin kabul edilebilir durumda olduğunu belirlemişlerdir. Gümüş vd. (2016), Kastamonu Üniversitesi'nde öğrenim gören Azeri ve Türk uyruklu üniversite öğrencilerinin yenilikçilik eğilimlerini incelemişlerdir. Öğrencilerin yenilikçilik eğilimlerinin düşük olduğunu tespit etmişlerdir.

Türk Kültürü'nün özelliklerini taşıyan Azerbaycan'da öğrenim gören Azeri uyruklu ve Türkiye'de öğrenim gören Türk uyruklu öğrencilerin sosyal sermaye, kültürel sermaye, sosyal yenilikçilik seviyelerinin ve her üç kavramın birlikte incelendiği araştırmalara pek rastlanılmamıştır. Milletlerin potansiyel kaynağı olan sosyal sermaye ve kültürün Türklük çatısı altında incelenmesi, mevcut kaynakların düzeyi ve kullanılabilirliğini keşfetmek açısından bu araştırmanın ilgili yazına ve Türk Dünyası'na katkıda bulunacağı düşünülmektedir.

\section{Yöntem}

Türk Kültürü'nde sosyal sermaye, kültürel sermaye ve sosyal yenilikçiliğin birbiri ile olan ilişkisinin araştırıldığ çalışmada nicel metot tercih edilmiş̧ir. İlgili kavramların ölçümünde anket kullanılmıştır. Araştırmanın amacına uygun olarak "örgüt, birey ya da grupların durumunu ortaya koyan betimleyici araştırma yöntemi” seçilmiştir (Altunış1k 2012: 71).

\section{Araştırmanın Amacı}

$\mathrm{Bu}$ çalışmada toplumsal gelişmeyi etkileyen kültür öğelerinden sosyal sermaye, kültürel sermaye ve sosyal yenilikçilik kavramları açıklanmıştır. Türk Kültürü bağına sahip iki ülke olan Türkiye'de ve Azerbaycan'da öğrenim gören üniversite öğrencilerinin sosyal sermaye, kültürel sermaye, sosyal yenilikçilik düzeyleri incelenmiş ve karşılaştırma yapılmıştır. İki ülkeyi ilgili kavramlar üzerinden çalışan araştırmalara pek rastlanılmamış olması ve her iki ülkenin bağlarının kuvvetlendireceği düşüncesi bu çalışmayı önemli kılmaktadır.

\section{Evren - Örneklem}

Araştırmanın evrenini Türkiye’yi temsilen Kocaeli Üniversitesi Uzay Bilimleri ve Havacılık Fakültesi havacılık yönetimi öğrencileri ile Azerbaycan'1 temsilen Azerbaycan Devlet Pedagoji Üniversitesi filoloji, tarih, pedagoji, edebiyat bölümü öğrencileri oluşturmaktadır. Belirtilen bölümlerde öğrenim gören öğrenciler kolayda örneklem yöntemine göre seçilerek araştırma örneklemini oluşturmuşlardır. Araştırmanın örneklemi 196 öğrenciden oluşmaktadır. Araştırmanın uygulaması 2019 yılı nisan-haziran ayları arasında gerçekleştirilmiştir. Sosyal sermaye ölçeğinin sadece stratejik güven boyutunun anket soruları kapsamına alınmasının nedeni ise; ölçeğin toplam soru sayısının çok olması, sıkıcılık yaratabileceğinden cevaplanma olasılığını azaltması düşüncesinden kaynaklanmaktadır. Anket formunda üç ölçeğin yanı sıra uyruk, yaş, cinsiyet, bölüm, gelir olarak beş adet demografik değişkene ait soru da bulunmaktadır.

\section{Veri Toplama Araçları}

Sosyal yenilikçilik ölçeği; Halaç vd. (2014) tarafindan geliştirilen ölçek sekiz madde ve tek boyuttan oluşmaktadır. Ölçeğin güvenirliği 0,85 olarak hesaplanmıştır. 
Sosyal sermaye stratejik güven ölçeği; Uçar (2016) tarafından geliştirilen ölçek dokuz maddeli tek bir boyuta sahiptir ve güvenirliği 0,84 'tür.

Kültürel sermaye ölçeği; Avcı ve Yaşar (2014) tarafından geliştirilmiştir. Ölçek otuz madde, kültürel potansiyel, kültürel bilinç, kültürel katılım, entelektüel sermaye olmak üzere dört boyuttan oluşmaktadır ve güvenirliği 0,94 olarak bulunmuştur.

Anket beşli likert ölçeğine göre düzenlenmiştir. Katılımcılardan 1 "kesinlikle katılmıyorum" dan 5 "kesinlikle katıllyorum" ifadesine kadar olan ifadelerden birini seçmelerini istenmiştir.

\section{Verilerin Analizi}

Araştırmada; açıklayıcı faktör analizi, korelasyon, regresyon analizi, t-testi, tek yönlü varyans analizi yapılmıştır. Verilerin analizi SPSS21 versiyonu kullanılarak gerçekleştirilmiştir. Analizler 0,05 anlamlılık düzeyi olarak kabul edilerek yapılmıştır. Araştırmanın amacına uygun olarak hazırlanan hipotezler aşağıda verilmiştir:

$\mathrm{H}_{1}$ : Azeri ve Türk uyruklu öğrencilerin sosyal sermaye stratejik güven düzeyi arasında anlamlı bir farklılık vardır.

$\mathrm{H}_{2}$ : Azeri ve Türk uyruklu öğrencilerin kültürel sermaye düzeyleri arasında anlamlı bir farkl1l1k vardır.

$\mathrm{H}_{3}$ : Azeri ve Türk uyruklu öğrencilerin sosyal yenilikçilik düzeyleri arasında anlamlı bir farklilik vardir.

$\mathrm{H}_{4}$ : Öğrencilerin demografik değişkenleri ile sosyal sermaye stratejik güven boyutu arasında bir farklılık vardır.

$\mathrm{H}_{5}$ : Öğrencilerin demografik değişkenleri ile kültürel sermaye ve alt boyutları arasında bir farklılık vardır.

$\mathrm{H}_{6}$ : Öğrencilerin demografik değişkenleri ile sosyal yenilikçilik arasında bir farklılık vardır.

\section{Bulgular}

Araştırmada kullanılan ölçeklere açıklayıcı faktör analizi uygulanmıştır. Kültürel sermaye ölçeği dört boyuta dağılmıştır. Ölçek faktör yük değeri 0,50'nin altında kalan maddeler analizden çıarılarak faktör analizine devam edilmiştir (Yaşlığlu, 2017). Bu nedenle madde 8-9-13 analiz kapsamı dışında bırakılmıştır. Ölçeğin açıkladığı toplam varyans oranı 44,016'dan 52,485'e yükselmiştir. Ölçeğin nihai dağ 11 mı; kültürel potansiyel alt boyutundaki maddelerin en yüksek faktör yükü 0,848 ; en düşük faktör yükü 0,776 olarak hesaplanmıştır. Katılım alt boyutundaki maddelerin en yüksek faktör yükü 0,795 ; en düşük faktör yükü 0,716 'dır. Entelektüel sermaye alt boyutundaki maddelerin en yüksek faktör yükü 0,755 ; en düşük faktör yükü 0,522 olarak bulunmuştur. Kültürel bilinç alt boyutundaki maddelerin en yüksek faktör yükü 0,763 ; en düşük faktör yükü 0,568 'dir. Kültürel sermaye ölçeğinin KMO değeri $0,864, X^{2}$ değeri 2504,145 ve p değeri 0,000 olarak hesaplanmıştır. Yazında faktör değerlerinin yüksek çıkması durumunda ve çok sayıda değişken olmadığında örneklem büyüklüğünün 100-200 arasında değişmesinin kabul edilebilir olduğu belirtilmektedir (Büyüköztürk 2002).

Sosyal sermaye ölçeği orijinaldeki tek boyutlu halini korumuş̧ur. Ancak madde 4 faktör yük değeri 0,50'nin altında kaldığ 1 için faktör analizinden çıkarılmıştır. Tekrarlanan faktör analizi sonucunda ölçeğin açıkladığ 1 toplam varyans oranı 40,312'den 44,109'a çıkmıştır. Ölçeğin en yüksek faktör yük değeri 0,775 ; en düşük faktör yük değeri 0,503 'tür. Sosyal sermaye ölçeğinin KMO değeri $0,865, \mathrm{X}^{2}$ değeri 685,598 ve $\mathrm{p}$ değeri 0,000 olarak hesaplanmıştır.

Sosyal yenilikçilik ölçeği tek boyutlu halini korumuştur. Faktör analizi sonucunda en yüksek faktör yük değeri 0,718; en düşük faktör yük değeri 0,552 olarak hesaplanmıştır. Ölçeğin açıkladığı 
toplam varyans oran1 41,494’tür. Sosyal yenilikçilik ölçeğinin KMO değeri 0,822, X² değeri 496,811 ve $p$ değeri 0,000 olarak hesaplanmıştır.

Tablo 1: Ölçeklere İlişkin KMO ve Güvenirlik Değerleri

\begin{tabular}{lllllll}
\hline Boyutlar & KMO & $\mathbf{X}^{\mathbf{2}}$ & $\mathbf{p}$ & $\begin{array}{l}\text { Açılanan } \\
\text { varyans }\end{array}$ & $\mathbf{N}$ & Cronbach Alfa \\
\hline Sosyal sermaye & 0,865 & 685,598 & 0,00 & 52,485 & 10 & 0,84 \\
Kültürel sermaye & 0,864 & 2504,145 & 0,00 & 44,109 & 28 & 0,90 \\
Sosyal yenilikçilik & 0,822 & 496,811 & 0,00 & 41,494 & 9 & 0,82 \\
\hline
\end{tabular}

Araştırmada kullanılan ölçeklere yapılan güvenirlik analizi sonucunda; kültürel sermaye ölçeğinin güvenirlik katsayısı 28 madde ile 0,908; sosyal sermaye ölçeğinin güvenirlik katsayıs1 10 madde ile 0,848 bulunmuştur. Ancak madde 3 güvenirliği düşürdüğünden analizden çıkarılmıştır. Tekrarlanan güvenirlik analizi cronbach alfa kat sayıs1 0,853 'tür. Sosyal yenilikçilik ölçeğinin güvenirlik katsayısı ise 9 madde ile 0,822 olarak hesaplanmıştır. 0,80 üzerinde olan güvenilirlik katsayılarına sahip ölçeklerin güvenirliğinin oldukça yüksek olduğu söylenebilir (Kalayc1 2009). Güvenirlik analizinden sonra gerçekleştirilen korelasyon değeri Tablo 2'de gösterilmiştir:

Tablo 2: Ölçekler Arası İlişki Değerleri

\begin{tabular}{|c|c|c|c|c|c|c|c|}
\hline Boyutlar & SY & SSSG & KS & KSP & KSB & KSK & KSE \\
\hline Sosyal yenilikçilik & 1 & $456^{* *}$ &, $632 * *$ & $486^{* * *}$ &, $461 * *$ &, $430 * *$ & ,591* \\
\hline $\begin{array}{l}\text { Sosyal sermaye } \\
\text { stratejik güven }\end{array}$ & & 1 &, $501 * *$ & ,468** &, $535 * *$ &, $275 * *$ &, $377 * *$ \\
\hline Kültürel sermaye & & & 1 &, $682 * *$ &, $766^{* *}$ &, $786^{* *}$ &, $873 * *$ \\
\hline Kültürel potansiyel & & & & 1 &, $531 * *$ &, $325^{* *}$ &, $452 * *$ \\
\hline Kültürel bilinç & & & & & 1 &, $438 * *$ &, $580 * *$ \\
\hline Kültürel katılım & & & & & & 1 &, $571 * *$ \\
\hline Entelektüel sermaye & & & & & & & 1 \\
\hline
\end{tabular}

$* * \mathrm{p}<0.01 * \mathrm{p}<0.05$

Korelasyon katsayı değeri "1"e ne kadar yaklaşırsa değișkenler arasında mükemmel derecede bir ilişki olduğu "+" ise doğru; "_" ise ters yönlü bir ilişki olduğu şeklinde yorumlanır (Altunışık vd, 2012: 228). Tablo 2'deki tüm değişkenler arasında doğru yönlü bir ilişki olduğu görülmektedir.

Tablo 3: Kültürel Sermaye ve Alt Boyutlarının Sosyal Yenilikçilik ile Regresyon Analizi

\begin{tabular}{|c|c|c|c|c|c|c|c|}
\hline & $\mathbf{R}$ & $\mathbf{R}^{2}$ & B & $\beta$ & $\mathbf{T}$ & $\mathbf{F}$ & p \\
\hline \multicolumn{8}{|l|}{$\begin{array}{l}\text { Bağımsız } \\
\text { değişken }\end{array}$} \\
\hline $\begin{array}{l}\text { Kültürel } \\
\text { Sermaye }\end{array}$ & ,632 & ,400 & ,228 & ,632 & 11,372 & 129,321 & ,00 \\
\hline $\begin{array}{l}\text { Kültürel } \\
\text { potansiyel }\end{array}$ & ,486 & ,236 & ,694 & ,486 & 7,746 & 60,000 & ,00 \\
\hline Külttürel bilinç & ,461 & ,212 &, 721 & 461 & 7,234 & 52,325 & ,00 \\
\hline Kültürel katılım & 430 &, 185 & ,425 & ,430 & 6,638 & 44,062 & ,00 \\
\hline Entelektüel &, 591 & ,349 &, 511 & ,591 & 10,201 & 104,059 & ,00 \\
\hline
\end{tabular}

Bağımlı değişken "Sosyal yenilikçilik" $p<0,05$

Kültürel sermayede gerçekleşen bir birimlik artış sosyal yenilikçilik üzerinde 0,632; kültürel potansiyelde gerçekleşen bir birimlik artış sosyal yenilikçilik üzerinde 0,486; kültürel bilinçte gerçekleşen bir birimlik artış sosyal yenilikçilik üzerinde 0,461 ; kültürel katılımda gerçekleşen bir birimlik artış sosyal yenilikçilik üzerinde 0,430; entelektüel sermayede gerçekleşen bir birimlik artış sosyal yenilikçilik üzerinde 0,591 artışa neden olmaktadır. 
Tablo 4: Kültürel Sermaye ve Alt Boyutlarının Sosyal Sermaye Stratejik Güven ile Regresyon

\begin{tabular}{llllllll} 
& \multicolumn{7}{c}{ Analizi } \\
\hline & $\mathbf{R}$ & $\mathbf{R}^{\mathbf{2}}$ & $\mathbf{B}$ & $\boldsymbol{\beta}$ & $\mathbf{T}$ & $\mathbf{F}$ & $\mathbf{p}$ \\
\hline Bağımsız değişken & & & & & & & \\
\hline Külttürel Sermaye &, 501 &, 251 &, 195 &, 501 & 8,055 & 64,880 & $\mathbf{, 0 0}$ \\
Kültürrel potansiyel &, 468 &, 219 &, 723 &, 468 & 7,382 & 54,499 & $\mathbf{, 0 0}$ \\
Külttürel bilinç &, 535 &, 286 &, 905 &, 535 & 8,818 & 77,749 & $\mathbf{, 0 0}$ \\
Kültürel katılım &, 279 &, 078 &, 298 &, 279 & 4,053 & 16,425 & $\mathbf{, 0 0}$ \\
$\begin{array}{l}\text { Entelektüel } \\
\text { sermaye }\end{array}$ &, 377 &, 142 &, 352 &, 377 & 5,661 & 32,049 & $\mathbf{, 0 0}$
\end{tabular}

Bağımlı değişken "Sosyal sermaye stratejik güven" $p<0,05$

Kültürel sermayede gerçekleşen bir birimlik artış sosyal sermaye stratejik güven üzerinde 0,501 ; kültürel potansiyelde gerçekleşen bir birimlik artış sosyal sermaye stratejik güven üzerinde 0,468; kültürel bilinçte gerçekleşen bir birimlik artış sosyal sermaye stratejik güven üzerinde 0,535 ; kültürel katılımda gerçekleşen bir birimlik artış sosyal sermaye stratejik güven üzerinde 0,279; entelektüel sermayede gerçekleşen bir birimlik artış sosyal sermaye stratejik güven üzerinde 0,377 artışa neden olmaktadır.

Tablo 5: Uyruğun Sosyal Yenilikçilik, Sosyal Sermaye Stratejik Güven, Kültürel Sermaye ve Alt Boyutlarıyla İlişkisi

\begin{tabular}{llrrrlll}
\hline Boyutlar & Uyruk & \multicolumn{1}{c}{ N } & \multicolumn{1}{c}{ ss. } & Ort. & t & \multicolumn{1}{l}{ F } & p \\
\hline Sosyal & TC & 100 & 6,30456 & 30,1000 & 1,822 &, 257 &, 070 \\
yenilikçilik & AZR & 96 & 6,61524 & 28,4167 & & & \\
Sosyal sermaye & TC & 100 & 6,38682 & $\mathbf{3 3 , 4 2 0 0}$ & 4,141 &, 882 & $\mathbf{, 0 0 0}$ \\
stratejik güven & AZR & 96 & 7,11213 & 29,4167 & & & \\
Kültürel & TC & 100 & 17,53525 & 86,3000 &,- 574 &, 493 &, 567 \\
Sermaye & AZR & 96 & 18,56891 & 87,7813 & & & \\
Kültürel & TC & 100 & 4,41023 & 17,3800 & 1,290 &, 673 &, 199 \\
potansiyel & AZR & 96 & 4,67899 & 16,5417 & & & \\
Kültürel bilinç & TC & 100 & 3,92056 & 16,7700 & 1,527 & 3,201 &, 128 \\
& AZR & 96 & 4,35919 & 15,8646 & & & \\
Kültürel katıllım & TC & 100 & 6,62773 & 17,8500 & $-2,407$ &, 011 &, $\mathbf{0 1 7}$ \\
& AZR & 96 & 6,36051 & $\mathbf{2 0 , 0 8 3 3}$ & & & \\
Entelektüel & TC & 100 & 7,09602 & 34,3000 &,- 922 &, 542 &, 358 \\
sermaye & AZR & 96 & 7,92586 & 35,2917 & & & \\
\hline
\end{tabular}

Yapılan t-testi sonucuna göre; uyruk ile sosyal sermaye stratejik güven arasında $p=$ $0,00<0,05$; uyruk ile kültürel katılım arasında $\mathrm{p}=0,017<0,05$ olduğundan anlamlı bir farklılık bulunmaktadır. Sosyal sermaye stratejik güven düzeyi Türk uyruklu öğrencilerde Azeri uyruklu öğrencilere göre daha yüksek bulunmuştur. $\mathrm{Bu}$ nedenle $\mathrm{H}_{1}$ hipotezi kabul edilmiştir. Kültürel katılım düzeyi Azeri uyruklu öğrencilerde Türk uyruklu öğrencilere göre daha yüksek bulunmuştur. Kültürel sermayenin sadece kültürel katılım düzeyi ile uyruk arasında farklılık görüldüğünden $\mathrm{H}_{2}$ hipotezi kısmen kabul edilmiştir. Uyruk ile diğer boyutlar arasında $\mathrm{p}>0,05$ olduğundan anlamlı bir farklılık görülmemiştir. $\mathrm{Bu}$ nedenle $\mathrm{H}_{3}$ hipotezi reddedilmiştir. 
Tablo 6: Cinsiyetin Sosyal Yenilikçilik, Sosyal Sermaye Stratejik Güven, Kültürel Sermaye ve Alt Boyutlarıla İlişkisi

\begin{tabular}{llrrllll}
\hline Boyutlar & Cinsiyet & \multicolumn{1}{c}{ N } & \multicolumn{1}{c}{ Ss. } & Ort. & t & \multicolumn{1}{l}{ F } & p \\
\hline Sosyal & Erkek & 87 & 5,78375 & 29,7816 &, 995 & 2,725 &, 321 \\
yenilikçilik & Kadın & 109 & 7,01467 & 28,8716 & & & \\
Sosyal sermaye & Erkek & 87 & 6,78997 & $\mathbf{3 2 , 5 9 7 7}$ & 2,054 &, 001 &, $\mathbf{0 4 1}$ \\
stratejik güven & Kadın & 109 & 7,11088 & 30,5505 & & & \\
Kültürel & Erkek & 87 & 16,00063 & 84,4943 & $-1,804$ & 1,434 &, 073 \\
Sermaye & Kadın & 109 & 19,31339 & 89,0459 & & & \\
Külttürel & Erkek & 87 & 4,52006 & 17,1494 &, 495 &, 101 &, 621 \\
potansiyel & Kadın & 109 & 4,59235 & 16,8257 & & & \\
Kültürel bilinç & Erkek & 87 & 3,84535 & 16,3448 &, 056 & 2,965 &, 956 \\
& Kadın & 109 & 4,40475 & 16,3119 & & & \\
Kültürel katılım & Erkek & 87 & 5,95768 & 17,6207 & $-2,593$ & 1,658 & $\mathbf{, 0 1 0}$ \\
& Kadın & 109 & 6,87858 & $\mathbf{2 0 , 0 0 0 0}$ & & & \\
Entelektüel & Erkek & 87 & 6,73975 & 33,3793 & $-2,413$ &, 615 &, $\mathbf{0 1 7}$ \\
sermaye & Kadın & 109 & 7,92621 & $\mathbf{3 5 , 9 0 8 3}$ & & & \\
\hline
\end{tabular}

Yapılan t-testi sonucuna göre; cinsiyet ile sosyal sermaye stratejik güven arasında $\mathrm{p}=$ $0,041<0,05$; cinsiyet ile kültürel katılım arasında $\mathrm{p}=0,010<0,05$; cinsiyet ile entelektüel sermaye arasında $\mathrm{p}=0,017<0,05$ olduğundan anlamlı bir farklılık bulunmaktadır. Sosyal sermaye stratejik güven düzeyi erkek öğrencilerde kadın öğrencilere göre; kültürel katılım düzeyi, entelektüel sermaye düzeyi kadın öğrencilerde erkek öğrencilere nazaran daha yüksek bulunmuştur. Diğer boyutların $p$ değeri $>0,05$ olduğundan istatistiki bir anlamlılık görülmemiştir.

Tablo 7: Gelir ile Kültürel Sermaye, Sosyal Yenilikçilik, Sosyal Sermaye Stratejik Güven İlişkisi

\begin{tabular}{|c|c|c|c|c|c|}
\hline Boyut & Gelir & $\mathbf{N}$ & SS. & $\mathbf{F}$ & $\mathbf{p}$ \\
\hline & 1499 TL ve daha az & 162 & 17,48188 & & \\
\hline \multirow{3}{*}{ Kültürel Sermaye } & $1500-2999 \mathrm{TL}$ & 24 & 21,61014 & & \\
\hline & 3000 TL ve üzeri & 10 & 15,71305 & 1,434 & ,241 \\
\hline & 1499 TL ve daha az & 162 & 4,54655 & & \\
\hline \multirow[t]{3}{*}{ Kültürel potansiyel } & $1500-2999 \mathrm{TL}$ & 24 & 4,60446 & & \\
\hline & 3000 TL ve üzeri & 10 & 4,27525 & 1,446 & ,238 \\
\hline & 1499 TL ve daha az & 162 & 4,04230 & & \\
\hline \multirow[t]{3}{*}{ Kültürel bilinç } & $1500-2999 \mathrm{TL}$ & 24 & 4,84973 & & \\
\hline & 3000 TL ve üzeri & 10 & 3,53396 & 2,438 & ,090 \\
\hline & 1499 TL ve daha az & 162 & 6,49406 & & \\
\hline \multirow[t]{2}{*}{ Kültürel katılım } & $1500-2999 \mathrm{TL}$ & 24 & 7,10366 & & \\
\hline & 3000 TL ve üzeri & 10 & 6,97296 &, 556 &, 574 \\
\hline \multirow[t]{4}{*}{ Entelektüel sermaye } & 1499 TL ve daha az & 162 & 7,31385 & & \\
\hline & $1500-2999 \mathrm{TL}$ & 24 & 8,93089 & & \\
\hline & 3000 TL ve üzeri & 10 & 6,81175 & 1,214 & ,299 \\
\hline & 1499 TL ve daha az & 162 & 6,18869 & & \\
\hline \multirow[t]{3}{*}{ Sosyal yenilikçilik } & $1500-2999 \mathrm{TL}$ & 24 & 7,91623 & & \\
\hline & 3000 TL ve üzeri & 10 & 6,62403 & 2,757 & ,066 \\
\hline & 1499 TL ve daha az & 162 & 6,99001 & & \\
\hline Sosyal sermaye & $1500-2999 \mathrm{TL}$ & 24 & 6,28649 & & \\
\hline stratejik güven & 3000 TL ve üzeri & 10 & 6,19677 & 5,371 &, 005 \\
\hline
\end{tabular}

Yapılan tek yönlü varyans analizi sonucuna göre; gelir ile sosyal sermaye stratejik güven boyutu arasında $\mathrm{p}=0,005<0,05$ olduğundan anlamlı bir farklılık olduğu görülmektedir. Bu farklılığın hangi gruptan kaynaklandığı ise Scheffe testi ile incelenmiştir: 
Tablo 8: Gelir ile Sosyal Sermaye Stratejik Güven Scheffe Testi

\begin{tabular}{lcccc}
\hline Boyut & \multicolumn{2}{c}{ Gruplararası eșleşme } & Ortalama farkı & p \\
\hline $\begin{array}{l}\text { Sosyal sermaye } \\
\text { stratejik güven }\end{array}$ & 1499 TL ve daha az & $1500-2999 \mathrm{TL}$ & $-4,31^{*}$ & 0,018 \\
\hline
\end{tabular}

Scheffe testi sonucuna göre; 1499 TL ve daha az gelire sahip katılımc1ların 1500-2999 TL gelire sahip katılımcılardan daha düşük sosyal sermaye stratejik güven düzeyine sahip olduğu görülmüştür.

Tablo 9: Bölüm ile Kültürel Sermaye, Sosyal Yenilikçilik, Sosyal Sermaye Stratejik Güven

\begin{tabular}{|c|c|c|c|c|c|}
\hline Bovut & Fakülte & $\mathbf{N}$ & ss. & $\mathbf{F}$ & $n$ \\
\hline & Havacıllk & 100 & 17,53525 & & \\
\hline & Pedagoji & 55 & 19,53160 & & \\
\hline & Filoloji & 31 & 14,95937 & 2,658 & ,034 \\
\hline \multirow[t]{4}{*}{ Kültürel Sermaye } & Edebiyat & 7 & 17,50918 & & \\
\hline & Tarih & 3 & 13,65040 & & \\
\hline & Havacılık & 100 & 4,41023 & & \\
\hline & Pedagoji & 55 & 4,91634 & & \\
\hline \multirow[t]{5}{*}{ Kültürel potansiyel } & Filoloji & 31 & 3,63170 & 3,967 & ,004 \\
\hline & Edebiyat & 7 & 3,13202 & & \\
\hline & Tarih & 3 & 4,72582 & & \\
\hline & Havacılık & 100 & 3,92056 & & \\
\hline & Pedagoji & 55 & 4,56506 & & \\
\hline \multirow[t]{6}{*}{ Kültürel bilinç } & Filoloji & 31 & 3,79813 & 3,008 & ,019 \\
\hline & Edebiyat & 7 & 3,64496 & & \\
\hline & Tarih & 3 & 2,00000 & & \\
\hline & Havacılık & 100 & 6,62773 & & \\
\hline & Pedagoji & 55 & 6,55014 & & \\
\hline & Filoloji & 31 & 5,73220 & 2,098 & ,083 \\
\hline \multirow[t]{3}{*}{ Kültürel katılım } & Edebiyat & 7 & 8,14453 & & \\
\hline & Tarih & 3 & 4,00000 & & \\
\hline & Havacılık & 100 & 7,09602 & & \\
\hline \multirow[t]{5}{*}{ Entelektüel sermaye } & Pedagoji & 55 & 8,25042 & 1,214 & 299 \\
\hline & Filoloji & 31 & 6,30327 & & \\
\hline & Edebiyat & 7 & 10,11129 & & \\
\hline & Tarih & 3 & 4,16333 & & \\
\hline & Havacılık & 100 & 6,30456 & & \\
\hline \multirow[t]{5}{*}{ Sosyal yenilikçilik } & Pedagoji & 55 & 7,50569 & & \\
\hline & Filoloji & 31 & 4,98061 & 1,659 & ,161 \\
\hline & Edebiyat & 7 & 5,43796 & & \\
\hline & Tarih & 3 & 5,29150 & & \\
\hline & Havacılık & 100 & 6,38682 & & \\
\hline \multirow{4}{*}{$\begin{array}{l}\text { Sosyal sermaye } \\
\text { stratejik güven }\end{array}$} & Pedagoji & 55 & 7,86318 & & \\
\hline & Filoloji & 31 & 6,37468 & 4,941 & ,001 \\
\hline & Edebiyat & 7 & 3,81725 & & \\
\hline & Tarih & 3 & 4,58258 & & \\
\hline
\end{tabular}

Yapılan tek yönlü varyans analizi sonucuna göre; bölüm ile kültürel sermaye $p=0,034<0,05$; kültürel potansiyel $\mathrm{p}=0,004<0,05$; kültürel bilinç $\mathrm{p}=0,019<0,05$; sosyal sermaye stratejik güven boyutu arasında $\mathrm{p}=0,001<0,05$ olduğundan anlamlı bir farklılık olduğu görülmektedir. Bu farklılığın hangi gruptan kaynaklandığı ise Scheffe testi ile incelenmiştir: 
Tablo 10: Bölüm ile Kültürel Sermaye, Kültürel Potansiyel, Kültürel Bilinç, Sosyal Sermaye Stratejik Güven Scheffe Testi

\begin{tabular}{lllcc}
\hline Boyut & \multicolumn{2}{c}{ Gruplararası eșleşme } & Ortalama farki & p \\
\hline Kültürel sermaye & Edebiyat & Tarih & $-34,95238^{*}$ & $\mathbf{, 0 3 8}$ \\
Kültürel potansiyel & Havacilık & Edebiyat & $5,52286^{*}$ & $\mathbf{, 0 1 4}$ \\
& Pedagoji & Edebiyat & $5,74286^{*}$ & $\mathbf{, 0 1 2}$ \\
Kültürel bilinç & Edebiyat & Tarih & $-8,42857^{*}$ & $\mathbf{, 0 2 5}$ \\
Sosyal sermaye & Havacıllk & Pedagoji & $4,22000^{*}$ & $\mathbf{, 0 0 2}$ \\
stratejik güven & & & & \\
\hline
\end{tabular}

Scheffe testi sonucuna göre; edebiyat bölümünde öğrenim gören öğrencilerin tarih bölümünde öğrenim gören öğrencilere kıyasla daha düşük kültürel sermaye düzeyine sahip olduğu görülmektedir. Her iki bölümde öğrenim gören öğrenciler Azerbaycan coğrafyasında yaşayan Azeri uyruklu öğrencilerden oluşmaktadır. Havacılık bölümünde öğrenim gören öğrencilerin edebiyat bölümünde öğrenim gören öğrencilere göre; pedagoji bölümünde öğrenim gören öğrencilerin edebiyat bölümünde öğrenim gören öğrencilere göre daha yüksek kültürel potansiyel düzeyine sahip olduğu görülmektedir. Havacılık bölümünde öğrenim gören öğrenciler Türkiye coğrafyasında yaşayan Türk uyruklu, edebiyat ve pedagoji bölümünde öğrenim gören öğrenciler Azerbaycan coğrafyasında yaşayan Azeri uyruklu öğrencilerdir. Edebiyat bölümünde öğrenim gören öğrencilerin kültürel bilinç düzeyleri tarih bölümünde öğrenim gören öğrencilere kıyasla daha düşüktür. Havac1lık bölümünde öğrenim gören öğrencilerin sosyal sermaye stratejik güven düzeylerinin pedagoji bölümünde öğrenim gören öğrencilere göre daha yüksek olduğu görülmektedir.

Tablo 11: Yaş ile Kültürel Sermaye, Sosyal Yenilikçilik, Sosyal Sermaye Stratejik Güven İlişkisi

\begin{tabular}{|c|c|c|c|c|c|c|c|}
\hline Boyutlar & Yaş & $\mathbf{N}$ & ss. & Ort. & $\mathbf{t}$ & $\mathbf{F}$ & $\mathbf{p}$ \\
\hline Sosyal & 26 yaş ve altı & 194 & 6,50729 & 29,3247 & 1,897 & 1,157 & ,296 \\
\hline yenilikçilik & $27-33$ yaş & 2 & 3,53553 & 24,5000 & & & \\
\hline Sosyal sermaye & 26 yaş ve altı & 194 & 7,02116 & 31,5361 & 6,729 & 2,870 & ,038 \\
\hline stratejik güven & $27-33$ yaş & 2 & 1,41421 & 24,0000 & & & \\
\hline Kültürel & 26 yaş ve altı & 194 & 18,05805 & 87,0103 &,- 110 & ,004 & ,930 \\
\hline Sermaye & 27-33 yaş & 2 & 19,09188 & 88,5000 & & & \\
\hline Kültürel & 26 yaş ve altı & 194 & 4,55479 & 17,0000 & 994 & , 200 & ,499 \\
\hline potansiyel & $27-33$ yaş & 2 & 4,24264 & 14,0000 & & & \\
\hline Kültürel bilinç & $\begin{array}{l}26 \text { yaş ve alt1 } \\
27-33 \text { yas }\end{array}$ & $\begin{array}{r}194 \\
2\end{array}$ & $\begin{array}{l}4,14219 \\
7,07107\end{array}$ & $\begin{array}{l}16,3093 \\
18,0000\end{array}$ &,- 338 & ,920 & ,792 \\
\hline Kültürel katılım & 26 yaş ve altı & 194 & 6,60108 & 18,9227 &,- 684 & ,693 & ,614 \\
\hline & 27-33 yaş & 2 & 4,24264 & 21,0000 & & & \\
\hline Entelektüel & 26 yaş ve altı & 194 & 7,54519 & 34,7784 &,- 282 & ,965 &, 822 \\
\hline sermaye & 27-33 yaş & 2 & 3,53553 & 35,5000 & & & \\
\hline
\end{tabular}

Yapılan t-testi sonucuna göre; yaş ile sosyal sermaye stratejik güven arasında $p=0,038<0,05$ olduğundan anlamlı bir farklılık bulunmaktadır. Bu sonuç 26 ve altındaki öğrenciler lehine bulunmuştur. Yaş ile diğer boyutlar arasında $\mathrm{p}>0,05$ olduğundan istatistiksel olarak farklılık bulunamamıştır.

Öğrencilerin demografik özelliklerinden cinsiyet, gelir, bölüm, yaş ile kültürel sermaye, sosyal yenilikçilik, sosyal sermaye stratejik güvene ilişkin analiz sonuçları incelendiğinde hipotezlerden $\mathrm{H}_{4}$ kabul edilmiştir, $\mathrm{H}_{5}$ kısmen kabul edilmiş, $\mathrm{H}_{6}$ reddedilmiştir. 


\begin{tabular}{|c|c|}
\hline \multicolumn{2}{|l|}{ Tablo 12: Hipotezlerin Kabul-Red Durumu } \\
\hline Hipotezler & Kabul-Red Durumu \\
\hline $\begin{array}{l}\mathrm{H}_{1} \text { : Azeri ve Türk uyruklu ögrencilerin sosyal sermaye stratejik güven düzeyi } \\
\text { arasında anlamlı bir farklılık vardır. }\end{array}$ & Kabul \\
\hline $\begin{array}{l}\mathrm{H}_{2} \text { : Azeri ve Türk uyruklu öğrencilerin kültürel sermaye düzeyleri arasında } \\
\text { anlamlı bir farklılık vardır. }\end{array}$ & Kismen Kabul \\
\hline $\begin{array}{l}\mathrm{H}_{3} \text { : Azeri ve Türk uyruklu öğrencilerin sosyal yenilikçilik düzeyleri arasında } \\
\text { anlamlı bir farklılık vardır. }\end{array}$ & Red \\
\hline $\begin{array}{l}\mathrm{H}_{4} \text { : Öğrencilerin demografik değişkenleri ile sosyal sermaye stratejik güven } \\
\text { boyutu arasında bir farklılık vardır. }\end{array}$ & Kabul \\
\hline $\begin{array}{l}\mathrm{H}_{5} \text { : Öğrencilerin demografik değişkenleri ile kültürel sermaye ve alt boyutları } \\
\text { arasında bir farklılık vardır. }\end{array}$ & Kismen Kabul \\
\hline $\begin{array}{l}\mathrm{H}_{6} \text { : Öğrencilerin demografik değişkenleri ile sosyal yenilikçilik arasında bir } \\
\text { farklılık vardır. }\end{array}$ & Red \\
\hline
\end{tabular}

Araştırmanın hipotezlerine ait sonuçlar bulgular incelenerek tablolaştırılmıştır. Hipotezlerin sonucuna ilişkin bulgular tartı̧̧ma, sonuç ve öneriler kısmında yorumlanarak tartışılmıştır.

\section{Tartışma, Sonuç ve Öneriler}

Kültürün o millete ait bir zenginlik olduğu düşünüldüğünde; sosyal sermaye, kültürel sermaye ve sosyal yenilikçilik kavramları kültüre ait unsurlar olarak öne çıkmaktadır. Bir ülkenin gelişmişliği sosyal sermayesini, kültürel sermayesini etkin kullanmasına bağlıdır. Bu çalışmada örneklem olarak seçilen öğrenciler kendi ülkelerine ait topraklarda yaşamlarını devam ettirmektedirler. Başka bir deyişle Türk ya da Azeri uyruklu öğrenciler kendi ülkelerinin kültürel ikliminde yer alarak bu çalışmaya katılmışlardır. Bu çalışmanın amacını; aynı kültüre mensup iki farklı ülkenin gençlerinin sosyal sermaye, kültürel sermaye ve sosyal yenilikçilik düzeyleri arasında farklılık olup olmadığını incelemek oluşturmaktadır.

Türkiye'de yaşayan Türk uyruklu öğrencilerin sosyal sermaye stratejik güven düzeylerinin Azerbaycan'da yaşayan Azeri uyruklu öğrencilerden daha yüksek olduğu görülmüştür. $\mathrm{H}_{1}$ hipotezi kabul edilmiştir. $\mathrm{Bu}$ durumun nedeni olarak; her iki ülkenin kökenlerinin Türk olduğu düşünüldüğünde aynı kültürü paylaşan öğrencilerin, ülkelere ait coğrafi, ekonomik, stratejik konum gibi öğelerden etkilenmiş olabileceği düşünülmektedir.

Kültürel sermayeye ilişkin sonuçlar incelendiğinde Azeri uyruklu öğrencilerin kültürel katılım düzeyleri Türk uyruklu öğrencilerden daha yüksek bulunmuştur. $\mathrm{H}_{2}$ hipotezi kısmen kabul edilmiştir. Kültürel sermayenin bir boyutu olan kültürel katılımın Azeri uyruklu öğrencilerin lehine çıkması onların kültürel öğelerine, kültürel miraslarına daha fazla sahip çıkmalarından kaynaklandığı düşünülmektedir.

Aynı kültüre mensup her iki ülkeyi temsil eden öğrencilerin sosyal yenilikçilik düzeyleri arasında bir farklılık görülmemiştir. $\mathrm{H}_{3}$ reddedilir. Bu bulguların tam tersine Gümüş vd. (2016) Türk uyruklu öğrencilerin Azeri uyruklu öğrencilere göre daha yüksek sosyal yenilikçilik eğilimine sahip olduklarını tespit etmişlerdir. Türk kültürüne üye üniversite öğrencilerinin sosyal yenilikçilik düzeylerinin artırılması yükseköğretimde verilecek olan derslerle, toplumun ihtiyacıyla ilişkili olduğu düşünülmektedir. Sosyal yenilikçiliği teşvik edecek her türlü destek ve kaynak üniversite öğrencilerine sağlanmalıdır. Kültürel sermaye ile sosyal yenilikçilik arasındaki pozitif yönlü ilişki 
düşünüldüğünde; üniversite öğrencilerin desteklenmesi; gelecekte iş hayatına atılacak olan bireylerin ekonomiyi ve toplum refahını güçlendirmesi demektir.

Azerbaycan ve Türkiye'de öğrenim gören Türk öğrencilerin karşılaştırılmasının yanı sıra sosyal sermaye, kültürel sermaye, sosyal yenilikçilik düzeylerini etkilediği düşünülen demografik değişkenlerin tespit edilmesi de amaçlanmıştır. Yaş, bölüm, gelir, cinsiyet, uyruk ile sosyal sermaye stratejik güven arasında anlamlı bir farklılık olduğundan $\mathrm{H}_{4}$ kabul edilmiştir. Bulgular Tatlı (2013)'nın bulgularıyla desteklenmektedir. Tatlı (2013) cinsiyetin ve gelirin sosyal sermaye düzeyini farklılaştırdığgnı belirtmektedir. Ancak Başak ve Öztaş (2010)'ın araştırma sonucunu göre cinsiyet ile sosyal sermayenin güven boyutu arasında anlamlı bir farklılık görülmemiştir. Abdioğlu ve Yavuz (2013)'un araştırma bulguları da demografik faktörlerin sosyal sermayenin güven boyutunu etkilediğini göstermektedir. Benzer bir araştırma sonucu da Başak ve Öztaş (2010: 52) tarafindan bulgulanmış; sosyal sermayenin oluşumunu sağlayan öncüllerden birinin toplumsal sınıf olduğu yani gelir, eğitim gibi demografik faktörlerin sosyal sermaye düzeyini etkilediği belirlenmiştir.

Bölüm, cinsiyet, uyruk ile kültürel sermaye veya boyutları arasında anlamlı bir farklılık görüldüğünden $\mathrm{H}_{5}$ kısmen kabul edilmektedir. Yanıklar (2010); Yaşar (2016) demografik değişkenlerin kültürel sermayeyi farklılaştırdığını belirtmişlerdir. Sosyal yenilikçilikle demografik değişkenler arasında anlamlı bir farklılık olmadığından $\mathrm{H}_{6}$ reddedilir. Bu bulguların tersine Özdemir ve $\operatorname{Ar}(2015)$ demografik değişkenlerin sosyal yenilikçiliği yordadığını ifade etmişlerdir.

Öğrencilerin sosyal sermaye stratejik güven düzeyleri; erkek öğrencilerde daha yüksek, bin beş yüz TL'den daha az gelire sahip öğrencilerde daha düşük olduğu ancak yirmi altı ve altı yaş grubu öğrencilerde daha yüksek olduğu görülmüştür. Bunun yanı sıra Havacılık yönetimi okuyan Türk uyruklu öğrencilerdeki sosyal sermaye stratejik güven düzeylerinin Azeri uyruklu pedagoji bölümünde okuyan öğrencilere göre daha yüksek olduğu görülmektedir. Ataerkil bir toplum yapısına sahip olan her iki ülke mensuplarında cinsiyetin güven düzeyini artırdığını belirtmek mümkündür. Bunun yanı sıra en düşük gelir seviyesinde sosyal sermaye stratejik güven düzeyinin düşük çıkması maddiyatın güveni etkilemesi şeklinde yorumlanabilmektedir. Stratejik bir boyut olarak güvenin işlem maliyeti, vekalet teorisi, örgütsel adalet gibi kavramların temelini oluşturduğu unutulmamalıdır.

Kadınların kültürel katılım düzeylerinin erkeklerden yüksek olması, kültürel açıdan dişil kültürün özelliklerinin cinsiyete yansımasıyla açıklanabilmektedir. Entelektüel sermaye düzeyleri de kadın öğrencilerde yüksek çıkmışır. Bu açıdan kadınların bilgi birikimlerinden katma değer yaratacak şekilde yararlanmak her iki ülkenin yararına olacaktır. Ayrıca kültürel sermayenin edebiyat ve tarih bölümünde öğrenim gören Azeri uyruklu öğrenciler arasında farklılık göstermesi tarih eğitimi alan öğrencilerin kültürel sermayelerinin yüksek çıkması bölüm odaklı olarak tamamen kültürel bilince sahip olmaktan kaynaklanmaktadır. Bunun yanı sıra Türk uyruklu öğrenciler olan havacılık yönetiminde öğrenim gören öğrencilerin Azeri uyruklu edebiyat bölümünde öğrenim gören öğrencilerden kültürel potansiyel düzeyleri daha yüksek bulunmuştur. Bu sonuç Türk uyruklu öğrencilerin Türkiye'deki kültürel iklimden, coğrafyadan etkilenmeleri şeklinde yorumlanmaktadır. Ek olarak Azeri uyruklu öğrenciler arasında tarih bölümünde öğrenim gören öğrencilerin kültürel bilinç düzeyleri edebiyat bölümünde öğrenim gören öğrencilerden daha yüksek olması da bölümün içeriğinden ve bölümde verilen eğitimin neden olduğu düşünülmektedir.

Sosyal yenilikçilik yönünden iki ülke arasında bir farklılık görülmemiştir. Bu durumun Türkiye ve Azerbaycan'ın belirsiz ve yeterli iş güvencesi ortamına sahip olamadığından kaynaklandığı düşünülmektedir. Kültürel sermaye düzeyindeki artışın sosyal yenilikçiliği de artıracağı unutulmamalıdır.

Kültürel özellik olarak hemşerilik, belirsizlikten kaçınma, kollektivist yaklaşımlar ilişkilere dayalı olarak güven unsurunun bir sonucudur. Cinsiyet temelli olan bulgular göz önünde bulundurulduğunda; Türk kültürünün bir öğesi olan kadınların desteklenmesi ekonomiye, ülkenin 
geleceğine yapılan bir yatırım olarak görülmektedir. İki ülke arasında işbirliği ve ortak kaynakların kullanımı sağlanarak, stratejik güven unsuru sağlanmalı ve Türk milletinin gücü ortaya çıarılmalıdır. Politikalar, eğitim sistemi gibi kültürel değerleri öne çıkaracak her türlü girişim desteklenmelidir. İleride yapılacak araştırmalara öneri olarak; bu çalışmanın araştırma kapsamı dışında kalan diğer Türk devletlerinde, farklı üniversitelerde de uygulanabileceğidir.

\section{Kaynakça}

Abdioğlu, H. ve Yavuz, S. (2013). İşletmelerde sosyal sermayenin ölçümlenmesi ve raporlanmasına yönelik bir araştırma. Afyon Kocatepe Üniversitesi İ̈BF Dergisi 15(1): 25-56.

Ağcasulu, H. (2017). Sosyal sermaye kavramı ve temel bakış açılarının karşılaştırılması. Vizyoner Dergisi, 8(17): 114-129.

Alver, K. (2010). Emile Durkheim ve kültür sosyolojisi. Sosyoloji Dergisi, 3(21): 199-210.

Anderson, A. ve Park, J. (2007). Entrepreneurial social capital. International Small Business Journal, 25(3): 245-272.

Ardahan, F. ve Ezici, M. (2015). İlköğretim sekizinci sınıf öğrencilerinin sosyal sermaye profili, sosyal sermaye ve başarı durumunun çeșitli demografik değișkenlere göre değerlendirilmesi: Antalya örneği. Sakarya University Journal of Education, 5(1): 16-36.

Arıcıŏlu, A. ve Ergin, R. A. (2009). Güven ya da sosyal sermaye nedir?: Konya sanayi bölgesinde sahip/yöneticiler üzerine bir araştırma. Selçuk Üniversitesi Sosyal Bilimler Enstitüsü Dergisi, (21), 25-43.

Avcı, Y. E. ve Yaşar, M. (2014). Kültürel sermaye ölçeği: Geçerlik ve güvenirlik çalışması. International Journal of Social Science Research, 3(4): 65-76.

Aydemir, M. A. ve Tecim, E. (2012). Türk toplumunda aile ve dinin sosyal sermaye potansiyeli. Selçuk Üniversitesi Sosyal Bilimler Enstitüsü Dergisi, 28: 43-59.

Baharloo, A. A. ve Naghavi, M. A. (July 4, 2012). The role of social capital in organizational commitment 1mprovement at Iran National Oil Products Distribution Company ( I.N.O.P.D.C), http://dx.doi.org/10.2139/ssrn.2100267, [erişim: 11.12.2019].

Başak, S. ve Öztaş, N. (2010). Güven ağbağları, sosyal sermaye ve toplumsal cinsiyet. Gazi Üniversitesi Ikktisadi ve İdari Bilimler Fakültesi Dergisi 12(1): 27-56.

Beşer, A. H. ve Hira, İ. (2017). Sosyal sermayeye eleştirel bakmak. Afyon Kocatepe Üniversitesi Sosyal Bilimler Dergisi, 19(1): 23-37.

Bourdieu, P. (1986). The forms of capital. J. Richardson (Ed.) Handbook of Theory and Research for the Sociology of Education. Greenwood: New York, 241-258. https://www.marxists.org/reference/subject/philosophy/works/fr/bourdieu-formscapital.htm

Boz, M., Buluk, B. ve Aysu, S.. (2017). Sosyal medya kullanımı ve sosyal sermaye ilişkisi: Çanakkale Onsekiz Mart Üniversitesi örneği. UiİiD-IJEAS, 16. UíK Özel Sayıs1, 633-648.

Burt, R. (1992). Structural holes: The social structure of competition. Cambridge, MA: Harvard University Press.

Büyüköztürk, Ş. (2002). Faktör analizi: temel kavramlar ve ölçek geliştirmede kullanımı. Kuram ve Uygulamada Eğitim Yönetimi. Güz (32), 470-483. 
Coleman, J. (1988). Social capital in the creation of human capital. American Journal of Sociology, 94 Supplement: 95-120.

Çeltikçi, O. (2016). Anadolu ve Azerbaycan coğrafyasında nazar inanışı üzerine uygulamaların karşılaştırılması. Uluslararası Edebiyat ve Toplum Sempozyumu Tam Metin Kitabı 261-278, 28-30 Nisan, Bartın.

Keskin, M. ve Dadaş, R. (2018). Kardeş ülke, ortak kültür. Uluslararası Azerbaycan-Türkiye Dil ve Kültür İlişkileri Sempozyumu 22-24 Kasım 2018, Bakü-Azerbaycan.

Dakhli, M. ve Clercq, D. (2004). Human capital, social capital, and innovation: a multicountry study. Entrepreneurship \& Regional Development, 16: 107-128.

Eşkinat, R. (2015). Sosyal sermayenin sürdürülebilir kalkınmaya etkisi. Anadolu University Journal of Social Sciences, 15(4): 75-90.

Field, J. (2005). Social capital and lifelong learning. Great Britain: Policy Press.

Giddens, A. (2014). Sosyoloji. İstanbul: Kırmızı Yayınları.

Gökçe, O. ve Uğuz, H. (2009). Selçuk Üniversitesi öğrencilerinin sosyal sermaye profilleri üzerine bir çalışma. Selçuk Üniversitesi İktisadi ve İdari Bilimler Fakültesi Sosyal ve Ekonomik Araştırmalar Dergisi, 9(18): 323-351.

Güçlü, N. (2003). Örgüt kültürü. Klrgızistan Manas Üniversitesi Sosyal Bilimler Dergisi, 6: 147159.

Gümüş, N., Kandemir, O. ve Benli, T. (2016). Azeri ve Türk öğrencilerin girişimcilik eğilimlerinin belirlenmesine yönelik Kastamonu Üniversitesi öğrencileri üzerinde bir araştırma. $I$. Milletlerarası Türkiye-Azerbaycan Münasebetleri Sempozyumu Bildiri Kitabı, 661-671 1214 Mayis 2016.

Halaç, D., Eren, H. ve Bulut, Ç. (2014). Sosyal yenilikçilik: Bir ölçek geliştirme. H.Ü. İktisadi ve İdari Bilimler Fakültesi Dergisi, 32(1): 165-190.

Herreros, F. (2004). The problem of forming social capital: Why trust?. Palgrave McMillian.

Horata, O. (2017). Türk Dünyası'nın kültürel ufukları: Tarihsel bağlam içinde genel bir değerlendirme. Bilig, 82: 117-131.

Kalaycı, Ş. (2009). SPSS uygulamalı çok değişkenli istatistik teknikleri. Ankara: Asil Yayınları.

Karahani, M. ve Patır, S. (2019). Üniversite öğrencilerinin bireysel yenilikçilik kapasitelerinin belirlenmesi. Sosyal Bilimler Enstitüsü Dergisi, 13: 42-58.

Maden, A. (1993). Yönetim ve kültür. Ankara Üniversitesi Dil ve Tarih-Coğrafya Fakültesi Dergisi, 1-2: 137-143.

Mutlu, H. H. (2016). Ulus karakteri ve edebiyat: ulus karakterinin edebi ürünlerine yansıması. Ana Dili Eğitimi Dergisi, 4(3): 372-389.

Nahapiet, J. ve Ghoshal, S. (1998). Social capital, intellectual capital and the organizational advantage, Academy of Management Review, 23: 242-266.

Narayan, D. ve Pritchett, L. (1999). Cents and sociability: Household income and social capital in Rural Tanzania. Economic Development and Cultural Change, 47(4): 871-897.

Nas, T. İ. (2017). İhracat performansında etkili olan entellektüel sermaye kriterlerinin analitik hiyerarşi süreci (AHS) yöntemi ile belirlenmesi ve ölçek önerisi ihracat performansında etkili 
olan entellektüel sermaye kriterlerinin analitik hiyerarşi süreci (AHS) yöntemi ile belirlenmesi ve ölçek önerisi. Tisk Akademi, 50-75.

Ozankaya, Ö. (1992). Ulusal toplumun ve ulusal kültürün kurucu ögeleri. Ankara Üniversitesi Siyasal Bilgiler Fakültesi Dergisi, 3(10): 213-225.

Özdemir, F. ve Ar, İ. M. (2015). Sosyal yenilik üzerine bir alan araştırması. Girişimcilik ve İnovasyon Yönetimi Dergisi 4(1): 17-43.

Raskoff, S. (2014). Social and cultural capital at school. https://www.everydaysociologyblog.com/2014/11/social-and-cultural-capital-atschool.html, [erişim: 01.10.2019].

Sargut, S. (2001). Kültürlerarası farklılaşma ve yönetim. Ankara: İmge Kitabevi.

Seki, İ. ve Aydın, R. (2019). Yaratıcı ekonomi yaklaşımı çerçevesinde üniversite öğrencilerinin sosyal sermaye seviyesinin belirlenmesine yönelik bir analiz. Ekonomi Bilimleri Dergisi, 11(1): 51-63.

Shane, S. (1992). Why do some societies invent more than others? Journal of Business Venturing, 7 : 29-46.

Shane, S. (1995). Uncertainty avoidance and the preference for innovation championing roles. Journal of International Business Studies, 26: 47-68.

Şan, M. K. ve Akyiğit, H. (2015). Sosyal sermaye tartışmaları ve Türkiye'de sosyal sermayenin ölçülmesi sorunu. Selçuk Üniversitesi Sosyal Bilimler Enstitüsü Dergisi, (34): 123-134.

Şirin, Y., Bilir, F. P. ve Öz, G. (2018). Üniversite öğrencilerinin sosyal girişimcilik eğilimleri: beden eğitimi ve spor yüksekokulu örneği. Gaziantep Üniversitesi Spor Bilimleri Dergisi, 3(3), 3547.

Tatl1, H. (2013). sosyal sermayenin bireylerin istihdamı üzerindeki etkisi hanehalk1 reisleri üzerine bir araştırma. Gazi Üniversitesi İktisadi ve İdari Bilimler Fakültesi Dergisi 15(3): 87-114.

Tittenbrun, J. (2013).Social capital trust and ideology. European Journal of Interdisciplinary Studies, 5(1): 8-25.

Toprak, E. ve Bozgeyikli, H. (2011). Öğretmen adaylarının sosyal sermaye düzeylerinin karş1laştırmalı incelenmesi (Erciyes Üniversitesi Örneği). Sosyal Bilimler Enstitüsü Dergisi, 31(2): 125-147.

Türk Dil Kurumu, [erişim: 01.10.2019]. https://sozluk.gov.tr/?kelime=k\%C3\%BClt\%C3\%BCr

Uçar, E. (2016). Sosyal sermaye ölçeğinin geçerlik ve güvenirlik çalışması. Ihlara Eğitim Araştırmaları Dergisi, 1(1): 19-40.

Uçar, M. E. (2010). Üniversite ögrencileri ve üniversiteden mezun olan bireylerin sosyal sermaye düzeylerinin benlik biçimleri ve çeşitti değişkenler açısından incelenmesi. Basılmamış Doktora Tezi, Ankara Üniversitesi Eğitim Bilimleri Enstitüsü, Ankara.

Yanıklar, C. (2010). Kültürel sermaye, eğitim ve toplumsal tabakalaşma: P1erre Bourdıeu'nün yeniden üretim kuramına eleştirel bir bakış. Sosyoloji Dergisi 22: 121-138.

Yaşar, R. (2016). Yoksulluk, akademik başarı ve kültürel sermaye ilişkisi. Sosyal Bilimler Dergisi 6(11): 202-237.

Yaşlıoğlu, M. (2017). Sosyal bilimlerde faktör analizi ve geçerlilik: keşfedici ve doğrulayıcı faktör analizlerinin kullanılması. İstanbul Üniversitesi İşletme Fakültesi Dergisi, 46(Özel Sayı): 74-85. 
Yıldız, Z. ve Topuz, H. (2011). Sosyal sermaye ve ekonomik kalkınma ilişkisi açısından Türkiye üzerine bir değerlendirme. Sosyal Siyaset Konferanslarl, 61(2): 201-226.

Zengin, Y. ve Tokucu, F. (2019). Küresel işletmecilikte kültürün önemi: Hofstede’nin kültürel boyutları çerçevesinde bir değerlendirme. Turkish Studies Economics, Finance, Politics, 14(3): 1135-1155. 